The cases were seen over a period of 19 months in 11 children whose ages ranged from 7 to 15 years. Nine were boys. The symptoms were sudden onset of dysuria, frequency, and haematuria. The urine contained red cells, but leucocytes were relatively scanty and bacterial cultures were negative. Infection with adenovirus 11 was confirmed in all 11 children by the demonstration of rising titres of antibody. The virus was also isolated from nine out of ten urines examined. The significance of these results was confirmed by the failure to isolate adenovirus from the urine of healthy children as well as from children with various other diseases. However, infection with adenovirus 11 was common in Sendai at the time of the infections, since $75 \%$ of children over 10 years of age had antibody to it.

Viruses are excreted in the urine in various viral diseases, such as measles, ${ }^{4}$ rubella, ${ }^{5}$ and mumps. ${ }^{6}$ The viruria which accompanies acute febrile virus diseases is usually symptomless, though transient minor disturbance of renal-function tests was found in 20 patients with mumps who were subjected to detailed investigation. ${ }^{7}$ Symptomless viruria has also been reported in an outbreak of adenovirus infection among naval recruits, ${ }^{8}$ but adenoviruses are almost certainly a rare cause of cystitis.

Isolation of virus from urine samples is a relatively straightforward procedure. It is rarely, if ever, attempted in cases of non-bacterial urethritis and cystitis at present. Though routine virological examination of the urine in these conditions is probably not yet justified, further studies are clearly required to assess the role of viruses in patients presenting with dysuria where no bacterial cause is found.

\section{Recovery from Subacute Encephalitis}

The condition variously referred to as subacute sclerosing leucoencephalitis and subacute inclusion-body encephalitis is generally believed to be invariably fatal. The term "leucoencephalitis" in this disease is really a misnomer, as pathological evidence clearly indicates that the entire brain is affected. Consequently subacute sclerosing panencephalitis would seem to be a more satisfactory title.

The clinical picture of this disorder and the accumulating evidence to suggest that it may be due to measles virus have recently been considered in these columns. ${ }^{1}$ The condition usually presents in childhood or adolescence with insidious intellectual deterioration or psychological disturbances, though in some cases major epileptic convulsions may be present from the outset. As the disease progresses the patient becomes demented and usually develops spastic weakness of all four limbs, with myoclonic spasms occurring between 4 and 12 times a minute. The electroencephalogram is virtu-

Brit. med. 7., 1968, 1, 189.

- Cobb, W., and Hill, D., Brain, 1950, 73, 392.

- Osetowska, E., in Encephalitides:-Proceedings of a Symposium, Antwerp, 1959, 1961, ed. L. van Bogaert, J. Radermecker, J. Hozay, and A. Lowenthal, p. 414. Amsterdam.

- Cobb, W. A., and Morgan-Hughes, J. A., f. Neurol. Neurosurg.

Kurtzke

Minneap.), 1956, 6, 371

- Simpson, J. A., Lancet, 1961, 2, 685.

- Pearce, J. M. S., and Barwick, D. D., Brit. med. F., 1964, 2, 611. ally diagnostic in that it shows generalized and bizarre slowwave discharges of short duration occurring repetitively against a background of comparative electrical silence and often in time with the myoclonic jerks of the limbs. ${ }^{2}$ In most cases death occurs in from 3 to 18 months from the development of the first symptom, but, as E. Osetowska ${ }^{3}$ has pointed out, survivals for four or five years have been described.

Recently W. A. Cobb and J. A. Morgan-Hughes ${ }^{4}$ have produced evidence to suggest that in occasional cases the disease process may become arrested, leaving the patient with permanent gross disabilities, and yet more rarely still it seems that recovery may take place. J. F. Kurtzke, J. A. Simpson, and J. M. S. Pearce and D. D. Barwick ${ }^{7}$ have reported single cases with prolonged clinical remission in which the diagnosis seemed reasonably certain on clinical and electroencephalographic evidence. Cobb and Morgan-Hughes ${ }^{4}$ describe two patients, aged 21 and 18 years, each of whom had suffered slowly progressive and characteristic illnesses lasting respectively 15 months and 2 years, with subsequent gradual recovery. In both cases the gold colloidal (Lange) curve in the cerebrospinal fluid was typically paretic and the E.E.G. changes were characteristic. In one case a brain biopsy from the frontal lobe confirmed the diagnosis and in the second it was equivocal. It seems probable that in neither case did intellectual capabilities return completely to normal. It may be significant that both patients were somewhat older than the usual age at which this disease is known to occur, but, as the authors point out, many cases showing an onset in early adult life have progressed to a fatal termination. Though both patients showed intellectual deterioration during the progressive stage of the illness, it may also be significant that disturbances of motor function were comparatively slight. It would therefore seem that these two patients suffered from the disease in a mild form, which not only allowed them to survive but also to recover their previous intellectual abilities to some degree.

No effective treatment for this condition is known. But though it remains one of considerable gravity, it can no longer be regarded as being universally fatal.

\section{Student Participation}

Probably no other profession has more often examined the education of those who aspire to practise it than has medicine. International conferences, a Royal Commission, the General Medical Council, and innumerable individual writers have contributed to the discussion in recent years. Since the views of the teachers rather than those still being taught overwhelmingly predominate, it is a valuable corrective to hear from the students themselves. Some of their views are set out in the latest publication ${ }^{1}$ from the British Medical Students' Association.

Two main themes underlie the B.M.S.A. report, and both of them have a bearing on some of the causes of unrest in universities here and abroad. The first is that the student should be given the opportunity to play an active part in his own education, and not simply be offered a succession of lectures and demonstrations by a hierarchy of beings from somewhere near outer space. The second is that what is taught should all along be seen to be relevant to the student's 
future work-namely, the practice of medicine and particularly the care of patients. It might be thought that both these objectives are clearly in mind at every medical school, but the evidence of the B.M.S.A. suggests that they are not. Among some specific criticisms the report makes is its view that there is too much useless overlapping between departments, so that time is wasted on teaching the same subject " with only a slight difference of bias." In addition, while some subjects are taught in excessive detail others are believed to be neglected, and among these the B.M.S.A. notes particularly genetics, statistics, first aid, the care of old people, and psychology and psychiatry. This list would certainly command general agreement.

Though the failure rate of medical students of $8.8 \%$ over the whole course is considerably below the average for university undergraduates $(13.3 \%),{ }^{3}$ it is generally recognized that examinations are at present "unreliable and otherwise unsatisfactory," to use the words of the Royal Commission, and that body suggested that a system of frequent assessment should replace the present more distantly spaced and more formidable hurdles. Unfortunately the B.M.S.A. report does not give a clear idea of what students themselves would believe to be a satisfactory test of competence, for it condemns " too frequent assessments" of factual knowledge but advocates "continuous, progressive assessment." There is nevertheless some truth in its view that too many students feel the need to study the technique of passing, for example, surgery examinations rather than the techniques of surgery.

In recommending that " all students should be encouraged to undertake some research project at some stage in their course " the B.M.S.A. report is following a fashion that causes far too little concern. The educational value of investigating a problem on one's own, with some guidance, is undoubted and should surely be a part of the education offered by any teacher who takes his job seriously. What more does the report intend ? At present it is quite usual for able students with a bent for it to play a part in the research being undertaken by their teachers or to compete for a prize by carrying out some project on their own. But there are undoubted dangers, which have not always been avoided in some countries abroad, in the misuse of animals and even patients when research is made part of an educational syllabus that all students must take. A more pressing question at present in medical schools-and in universities as a whole-is whether there is not far too much research of a trivial nature carried out to win friends and influence people. While the capacities to teach well and to do worthwhile research are occasionally combined in one individual, many students would probably warmly commend this plea from the report: "We would like to see more teachers appointed because of teaching ability rather than past research."

\footnotetext{
- Simpson, M. A., and Matthews, T., Report on Medical Education, 1968, British Medical Students' Association, 1968. B.M.A. House, London.

= Enquiry into Student Progress, 1968, University Grants Committee, 1968. H.M.S.O.

Brit. med. Y., 1968, 3, 390

- Report of the Royal Commission on Medical Education, 1965-68, 1968. Cmnd. 3569. H.M.S.O.
}

\section{Future of Paediatricians}

The first 20 years of the National Health Service made it possible to increase the number of trained paediatricians in Great Britain and they have had considerable influence on the pattern and quality of child care, in which there have been, and still need to be, great advances. It was therefore timely that last week a symposium should have been held in London on the future role and training of paediatricians in this country. Six visiting professors of paediatrics from leading centres in Europe attended. Funds for the meeting were provided by the International Children's Centre of Paris, and the arrangements were made by the Association for the Study of Medical Education in conjunction with the recently formed Academic Board of the British Paediatric Association.

Outlining the history of British paediatrics in his opening address, Professor Douglas Hubble reminded his audience that 26 years ago Sir James Spence's memorandum for the Nuffield Provincial Hospitals Trust erected the signposts that had pointed to su many of the advances in child care of the past 20 years. Certainly his audience shared his hope that this symposium would now act as a springboard for the next series of advances. During the first day's discussions on the present pattern of paediatric care and the education for it many paediatricians stressed their almost intolerable workload and their anxiety about how this must affect the service they were able to give their child patients. The majority of children are still treated in hospital by doctors who have seldom had any specific training in paediatrics, and they are treated in their homes by doctors who have seldom had more than six months' postgraduate training and sometimes none at all. In the future pattern of child care in the community and in hospital, discussed on the second day, some speakers considered the paediatricians would need more knowledge of community medicine and could not be expected to work in the isolation that some of them must do at present. They would have to be based on hospital departments large enough to carry the necessary facilities and nursing staff, and these departments would need to contain not fewer than 60 beds.

Facilities for teaching paediatrics to undergraduates were deemed inadequate in some of the London hospitals and often less than desirable in provincial teaching centres. Postgraduate training was thought to need more careful devising, and the now familiar view was expressed that the M.R.C.P. examination had in the past been apt to distort the training. In summing up Professor Hubble assured the conference that an invitation to look further into the help that may be gained for child care from a meeting between the British Paediatric Association through its academic board and the Royal College of General Practitioners would be accepted. He felt that they could usefully invite the Society of Medical Officers of Health to take part at a later date. In his view the preventive aspects of paediatrics had been undervalued, and if colleagues in adult medicine supported their efforts to improve child care at this stage it might prove to be one of the best ways of reducing the incidence of many of the diseases affecting the. next generation of adults. 